\title{
The lack of slow force response in failing rat myocardium: role of stretch-induced modulation of $\mathrm{Ca}$-TnC kinetics
}

\author{
Oleg Lookin ${ }^{1,2} \cdot$ Yuri Protsenko ${ }^{1}$
}

Received: 20 September 2018 / Accepted: 8 December 2018 / Published online: 18 December 2018

(c) The Physiological Society of Japan and Springer Japan KK, part of Springer Nature 2018

\begin{abstract}
The slow force response (SFR) to stretch is an important adaptive mechanism of the heart. The SFR may result in 20-30\% extra force but it is substantially attenuated in heart failure. We investigated the relation of SFR magnitude with $\mathrm{Ca}^{2+}$ transient decay in healthy (CONT) and monocrotaline-treated rats with heart failure (MCT). Right ventricular trabeculae were stretched from 85 to $95 \%$ of optimal length and held stretched for 10 min at $30{ }^{\circ} \mathrm{C}$ and $1 \mathrm{~Hz}$. Isometric twitches and $\mathrm{Ca}^{2+}$ transients were collected on 2, 4, 6, 8, 10 min after stretch. The changes in peak tension and $\mathrm{Ca}^{2+}$ transient decay characteristics during SFR were evaluated as a percentage of the value measured immediately after stretch. The amount of $\mathrm{Ca}^{2+}$ utilized by $\mathrm{TnC}$ was indirectly evaluated using the methods of $\mathrm{Ca}^{2+}$ transient "bump" and "difference curve." The muscles of CONT rats produced positive SFR and they showed prominent functional relation between SFR magnitude and the magnitude (amplitude, integral intensity) of $\mathrm{Ca}^{2+}$ transient "bump" and "difference curve." The myocardium of MCT rats showed negative SFR to stretch (force decreased in time) which was not correlated well with the characteristics of $\mathrm{Ca}^{2+}$ transient decay, evaluated by the methods of "bump" and "difference curve." We conclude that the intracellular mechanisms of $\mathrm{Ca}^{2+}$ balancing during stretch-induced slow adaptation of myocardial contractility are disrupted in failing rat myocardium. The potential significance of our findings is that the deficiency of slow force response in diseased myocardium may be diminished under augmented kinetics of $\mathrm{Ca}-\mathrm{TnC}$ interaction.
\end{abstract}

Keywords Slow force response $\cdot$ Rat myocardium $\cdot$ Heart failure $\cdot$ Isometric contraction $\cdot \mathrm{Ca}^{2+}$ transient

\section{Introduction}

The slow change in contractility after sudden stretch (slow force response, SFR) is an important regulator of pump function of the heart as this provides a long-term adaptation of the heart to the changed environmental conditions, the phenomenon known as the Anrep effect [1,2]. This phenomenon is found in the healthy mammalian and human

Electronic supplementary material The online version of this article (https://doi.org/10.1007/s12576-018-0651-3) contains supplementary material, which is available to authorized users.

Oleg Lookin

o.lookin@iip.uran.ru

1 Laboratory of Biological Motility, Institute of Immunology and Physiology, Ural Branch of Russian Academy

of Sciences, 106 Pervomayskaya St., Yekaterinburg 620049, Russian Federation

2 Ural Federal University, 19 Mira St., Yekaterinburg 620002, Russian Federation myocardium and observed in single cardiac cells and multicellular tissues as well as in the whole organ [3-7]. Impaired mechano-signaling to stretch in diseased myocardium, e.g., in heart failure, may lead to a lack of manifestation of SFR [8-11].

The increase in contractility (positive SFR) can be related either to extra calcium slowly accumulated in cardiac cells or slow modulation of function of intracellular molecular mechanisms involved in length-dependent activation of contraction, or both of them. The exact mechanisms remain unresolved so far, but possible pathways include activation of mechanosensitive membrane-spanning ion channels [6, 12], autocrine-paracrine regulation via the angiotensinendothelin pathway $[13,14]$ involving the contribution of reactive oxygen species [15-17] and transient receptor potential canonical $[18,19]$, to the activation of a sodiumhydrogen exchanger, store-operated calcium channels [20, 21], and length-dependent modulation of myofilaments by the giant protein titin [22-25]. The above mechanisms can be impaired under pathological conditions, e.g., in heart 
failure, and this can result in blunting or even a negative force response to sudden stretch [10]; however, there is evidence of substantial positive SFR in failing human myocardium [26]. Based on the fact that positive SFR is related to slowly increased $\mathrm{Ca}^{2+}$ content in cytosol/sarcoplasmic reticulum, the blunting or inversion of SFR (from positive to negative) in failing myocardium must be accompanied by contemporaneous changes in cytosolic calcium.

Our aim was to study the relation between slow force response magnitude (typically expressed as a percentage of the amplitude of the first twitch after a sudden stretch) and slow modulation of the cytosolic $\mathrm{Ca}^{2+}$ transient, both measured in the same muscle during the same slow response. We focused on the decay phase of the $\mathrm{Ca}^{2+}$ transient, not on its amplitude, as the relaxation phase of muscle contraction is of great importance in the regulation of the next beat [27, 28]. In the present study we provide new findings that relate the magnitude of SFR with the gradual slow effects on $\mathrm{Ca}^{2+}$ transient decay in healthy rat myocardium but not in the failing rat myocardium, where these effects were found to be substantially depressed.

\section{Materials and methods}

\section{Ethical approval}

The animals involved in the present study were cared for according to the Directive 2010/63/EU of the European Parliament and the Guide for the Care and Use of Laboratory Animals published by the US National Institutes of Health (NIH Publication No. 85-23, revised 1985); their use was approved by the local institutional ethics committee. Rats were obtained from the institutional animal house and maintained under a 12-h light-dark cycle with free access to standard chow and water.

\section{Experimental model of monocrotaline-induced heart failure}

Monocrotaline was used to develop pulmonary hypertension followed by severe right ventricular hypertrophy. Briefly, 4-week-old Wistar rats of both sexes (weighing 80-100 g) were randomly divided into control (normal myocardium) and monocrotaline-treated (hypertrophic myocardium) groups. Rats in the monocrotaline-treated group were given a single subcutaneous injection of saline solution containing monocrotaline $(2 \mathrm{ml} / \mathrm{kg}$; final concentration $50 \mathrm{mg} / \mathrm{kg}$ body weight), whereas rats in the control group were injected with an equivalent volume of saline solution. Monocrotaline-treated rats (MCT, $n=6$ ) were killed as soon as loss of body weight and dyspnea at rest became prominent $(\sim 3.5$ weeks after the treatment). Control rats (CONT, $n=6)$ were killed at the same age. The validity of the experimental model of pulmonary hypertension and severe hypertrophy/heart failure in young rats has been tested and confirmed in our recent study [29]. The above described treatment induced substantial increase in right ventricular mass with significant loss of left ventricular mass, indicating a marginal state between severe hypertrophy and heart failure (the morphometric indices relating to the heart are provided in Supplemental data, Table 1S). For uniformity, elsewhere in the text we use term "failing" to refer this state of the myocardium.

\section{Muscle isolation and data measurements}

Animals were anesthetized with $15 \mathrm{mg} / \mathrm{kg}$ zolazepam (Zoletil100 ${ }^{\circledR}$; Virbac, Carros, France) and killed by rapid cervical dislocation. The heart was quickly excised and placed in modified Krebs-Henseleit (K-H) solution (in $\mathrm{mM}: \mathrm{NaCl} 118.5 ; \mathrm{KCl} 4.2 ; \mathrm{MgSO}_{4} 1.2 ; \mathrm{CaCl}_{2} 2.5 ;$ glucose 11.1) equilibrated in $95 \% \mathrm{O}_{2}+5 \% \mathrm{CO}_{2}$ with $\mathrm{NaHCO}_{3}$ and $\mathrm{KH}_{2} \mathrm{PO}_{4}$ to maintain $\mathrm{pH}$ at 7.35. Trabeculae were dissected from the right ventricle, clipped to a force transducer and length servomotor (Muscle Research System; Scientific Instruments $\mathrm{GmbH}$, Heidelberg, Germany) in an experimental bath and continuously bathed in K-H solution. To monitor free cytosolic $\mathrm{Ca}^{2+}$, the muscles were preincubated in the saline containing calcium-sensitive fluorescent indicator $(5 \mu \mathrm{M}$ fura-2/AM $+0.2 \% \mathrm{w} / \mathrm{v}$ Pluronic F-127) during $\sim 1.5 \mathrm{~h}$ at room temperature and $0.2 \mathrm{~Hz}$ pacing rate. Prior to the measurements, the perfusion was continued in dye-free saline for $30 \mathrm{~min}$. Force, length and fura-2 intensity were sampled simultaneously at $10 \mathrm{kHz}$ using an analog-to-digital (A/D) and D/A data converter (PCI1716S; AdLink Technology, New Taipei City, Taiwan) and custom-made software running in a real-time environment (HyperKernel; Nematron, Ann Arbor, MI, USA) integrated with Windows XP (Microsoft; Redmond, WA, USA). Data were processed and analyzed off-line using custom-made software. Force values were transformed to tension values using the elliptical cross-sectional area of a muscle, calculated as $S=\pi d^{2} / 12$, where $d$ is the wider diameter of a muscle measured at slack length. Fura-2 intensity signals were obtained as a ratio of light intensities collected at $510-\mathrm{nm}$ wavelength by excitation at either $340 \mathrm{~nm}$ or $380 \mathrm{~nm}(F=\mathrm{F} 340 / \mathrm{F} 380)$ and presented here as $F / F_{0}$, where $F_{0}$ is a ratio measured in quiescent muscle at slack length (i.e., when no stretch is applied). All experiments were carried out at $30^{\circ} \mathrm{C}$ and $1 \mathrm{~Hz}$ pacing rate. All chemicals were purchased from Sigma-Aldrich (St Louis, MO, USA) except potassium losartan (Merck Sharp \& Dohme Corp, Haarlem, the Netherlands). 


\section{Slow force response protocol}

A muscle was released to the length where no passive force was developed; this length was taken to be the slack length. The muscle was then stretched gradually for approximately $2-3 \%$ of the slack length and allowed to equilibrate at the new length prior to further measurements. When no further increase in the amplitude of active tension was observed, the final length was taken to be the optimal length $\left(L_{\mathrm{MAX}}\right)$. A protocol of sudden stretch of isometrically contracting muscle from 85 to $95 \% L_{\mathrm{MAX}}$ was applied to measure slow changes in contractile activity of the muscle, i.e., slow force response (SFR), slow twitchto-twitch changes in certain characteristics. Rapid stretch was applied during $100 \mathrm{~ms}$ in between two twitches and muscle force and $\mathrm{Ca}^{2+}$ transients at the new length were recorded for $\sim 30 \mathrm{~s}$ around the time intervals of 2, 4, 6, 8 and $10 \mathrm{~min}$ after the stretch (see Fig. 3). To compare the expression of slow changes in contractility between individual muscles, we normalized the value of given characteristics in each twitch to the value obtained from the first twitch after stretch.

\section{The analysis of $\mathrm{Ca}^{2+}$ transient decay}

We focused our analysis on the decay phase of $\mathrm{Ca}^{2+}$ transient rather than $\mathrm{Ca}^{2+}$ transient amplitude (see Discussion for reason). We applied two distinct methods to reveal whether slow force response to stretch is related to slow (if any) changes in the decay of the $\mathrm{Ca}^{2+}$ transient: the method of "bump" (the first observation and further concept were introduced two decades ago [3] and described in detail elsewhere [30]) and the method of "difference curve."

It has been shown previously $[29,30]$ that there is a brief delay in $\mathrm{Ca}^{2+}$ transient decay ("bump") in stretched rat myocardium, compared to non-stretched muscle (Fig. 1a). The consistent effect of gradual muscle stretch is an increase in the magnitude of the "bump" (Fig. 1b). We evaluated the characteristics of the "bump" - amplitude, integral intensity, time-to-peak — during the development of the slow force response, according to our method [30, 31]. The amplitude of the "bump" was expressed as a percentage of the $\mathrm{Ca}^{2+}$ transient amplitude (normalized "bump" amplitude), the integral intensity of the "bump" was expressed as a percentage of the area calculated under the monotonic part of the $\mathrm{Ca}^{2+}$ transient, and the time-to-peak of the "bump", i.e.,
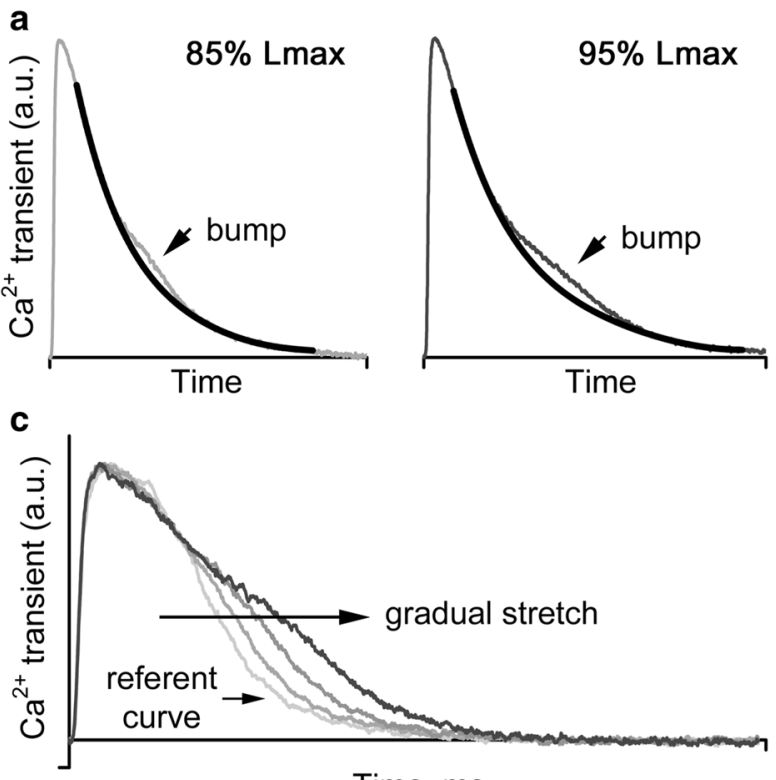

Time, ms
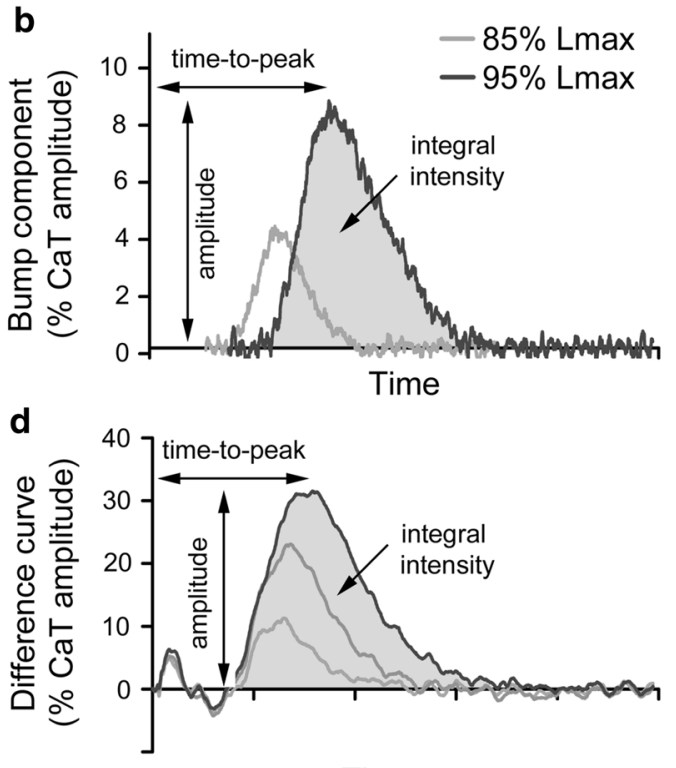

Time, ms
Fig. 1 The methods of "bump" and "difference curve" of $\mathrm{Ca}^{2+}$ transients. a $\mathrm{Ca}^{2+}$ transient traces obtained under low or high stretch of a muscle (e.g., $85 \%$ and $95 \% L_{\mathrm{MAX}}$ ) and normalized to their peaks. Thin line shows raw $\mathrm{Ca}^{2+}$ transient trace, thick line shows its monotonic component. The difference between the lines ("bump") is indicated by arrows. b The time-based "bump" traces obtained from the transients shown in panel a. Certain characteristics of the "bump" are used for the analysis, e.g., its amplitude, integral intensity (an area under the "bump" trace), time-to-peak. c The superposition of normalized $\mathrm{Ca}^{2+}$ transient traces obtained under gradual stretch of a muscle as indicated by a long arrow. The trace obtained under no or minimal stretch is assumed as referent curve and this curve is subtracted from any other curve in the set. $\mathbf{d}$ The superposition of timebased "difference curves" obtained from the transients shown in panel c. Like the "bump", the "difference curve" has certain characteristics, e.g., amplitude or integral intensity. Note that the difference curve has at least two components which are deflected upward ("positive" component) and downward ("negative" component). The characteristics shown here in panel $\mathbf{d}$ are related to the "positive" component of the "difference curve." Please see the text for a detailed description 
the time of maximal deflection of bumped part of the $\mathrm{Ca}^{2+}$ transient trace from its monotonic component, was evaluated relative to the $\mathrm{Ca}^{2+}$ transient time-to-peak.

We also developed another approach ("difference curve") in which we evaluated the difference between two $\mathrm{Ca}^{2+}$ transient traces obtained for two different conditions, e.g., for different time intervals during the slow force response. Prior to the calculation of "difference curve", $\mathrm{Ca}^{2+}$ transient traces were normalized to their respective peaks. As shown in Fig. 1c, a gradual stretch of rat cardiac muscle modifies the $\mathrm{Ca}^{2+}$ transient decay phase in a very distinct manner. If some condition is used as the referent, e.g., where lower stretch of the muscle is applied, then the corresponding $\mathrm{Ca}^{2+}$ transient trace can be subtracted from the trace obtained for another condition. Figure 1d demonstrates the series of "difference curves" retrieved from the $\mathrm{Ca}^{2+}$ transient traces obtained under gradual stretch of a muscle, shown in Fig. 1c. Like the "bump" curve, the "difference curve" can be characterized by certain features, including amplitude, integral intensity and time-to-peak of the curve. A common feature of the "difference curve" is that it has at least two distinct phases or components: one is being deflected upward ("positive" component, its characteristics are indicated in Fig. 1d) and another is being deflected downward ("negative" component). In the present study we focused on the "positive" component of the "difference curve" (referred to in figure legends as DC), which is larger and slower (see Discussion for reasons). It was evaluated by its amplitude, integral intensity (an area under this component of the difference curve) and time-to-peak (calculated from the time-topeak of $\mathrm{Ca}^{2+}$ transient). Also, as we used the $\mathrm{Ca}^{2+}$ transient measured immediately after stretch as the referent transient, we analyzed slow changes in the "difference curve" in a distinct manner, compared to the analysis of the "bump." At the time point of $0 \mathrm{~min}$ after stretch (immediately after stretch), no "difference curve" exists. Therefore, the amplitude and integral intensity of the "difference curve" are presented as a percentage of $\mathrm{Ca}^{2+}$ transient amplitude/integral intensity, not as a percentage of the first value after the stretch. The possible consequences of using the "difference curve" method specifically to analyze $\mathrm{Ca}^{2+}$ transients are discussed in detail in the appropriate section.

\section{Statistical analysis}

The number of preparations involved in the analysis is equal to the number of animals used and indicated in figure legends as " $n$. " The time-matched differences in peak tension and the characteristics of the $\mathrm{Ca}^{2+}$ transient decay phase between normal and failing myocardium during the development of slow force response (at $2 \mathrm{~min}$ after stretch, at $4 \mathrm{~min}$ after stretch, and so on) were evaluated by a Mann-Whitney $U$ test. The time-dependent effects in the same group, e.g., the comparison of the means for the 2-min vs 10-min time point, were tested by a Wilcoxon matched pairs test. Effects were considered significant at $P<0.05$. Data are presented either as median with $25-75 \%$ percentiles or as mean \pm SD . The statistical analysis was performed with Statistica 8.0 (StatSoft Inc.).

\section{Results}

\section{The magnitude of slow force response in normal and failing rat myocardium}

The magnitude of slow force response is presented here as a percentage of the amplitude of first twitch after sudden stretch. Figure 2 summarizes slow force responses measured in the muscles from CONT and MCT rats. Sudden stretch is accompanied by a gradual time-dependent increase in active tension in CONT rats, while MCT rats showed a negative response (Fig. 2). During the progression of slow response in contractility from the 2-min to the 10-min time point, the mean value of SFR magnitude in the CONT group increased from $105.9 \pm 2.5 \%$ to $110.9 \pm 6.0 \%$ of the first value after stretch (mean $\pm \mathrm{SD}$, significant difference, $P=0.046$ by Wilcoxon matched pairs test). In the group of monocrotalinetreated animals, the corresponding mean values of SFR magnitude were $93.5 \pm 5.0 \%$ and $93.7 \pm 6.3 \%$ (mean $\pm S D$, non-significant difference, $P=0.92$, Wilcoxon matched pairs test). At the end of the 10-min interval, the muscles from normal and failing rat hearts were significantly different in the SFR magnitude $(110.9 \pm 6.0 \%$ in CONT vs $93.7 \pm 6.3 \%$ in MCT, mean $\pm \mathrm{SD}, P=0.004$, Mann-Whitney $U$ test). Therefore, the failing rat myocardium was substantially different from the healthy hearts in the response to sudden mechanical stretch.

\section{Slow changes in "bump" characteristics in response to stretch}

In order to evaluate how the slow force response is related to (if any) slow changes in $\mathrm{Ca}^{2+}$ transient decay phase, we measured a series of $\mathrm{Ca}^{2+}$ transients around the time intervals of 2, 4, 6, 8 and 10 min after the sudden stretch was applied (Fig. 3) and analyzed the changes using the "bump" and "difference curve" methods separately. Please note that we used normalized $\mathrm{Ca}^{2+}$ transients, according to the reasons described in "Materials and methods."

The time-based changes in the normalized amplitude, integral intensity and time-to-peak of the $\mathrm{Ca}^{2+}$ transient "bump" measured in healthy and failing rat myocardium are shown in Fig. 4. The magnitude of the "bump", as assessed by its amplitude and integral intensity, was progressively elevated in CONT muscles during the SFR, 


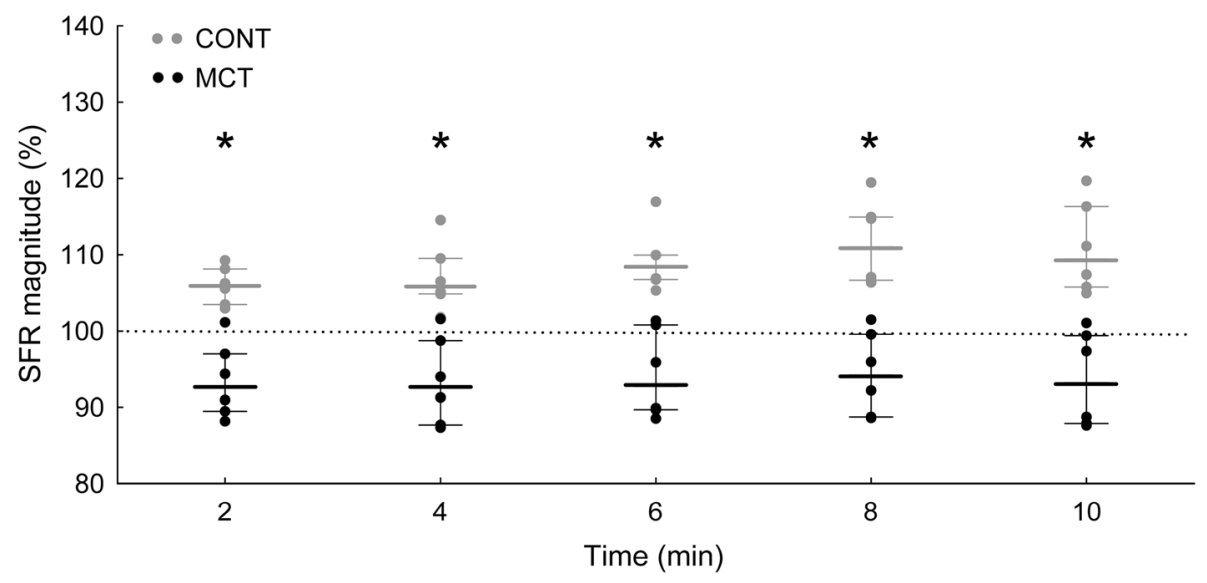

Fig. 2 The slow force response to sudden stretch in normal and failing rat myocardium. The slow change in isometric tension in response to sudden stretch in normal $(n=6)$ and failing $(n=6)$ rat myocardium. SFR magnitude is expressed as a percentage of the amplitude of first twitch after stretch. The dotted line shows the level of "no change."
Scatter-plots of raw data (dots), median values (long thick lines) and 25-75\% percentiles (short thin lines) are shown. Asterisks indicate that the mean values are significantly different between CONT and MCT groups for the given time (Mann-Whitney $U$ test, $P<0.05$ )
Fig. 3 The scheme demonstrating the simultaneous measurement of slow force response and $\mathrm{Ca}^{2+}$ transients at the preset time intervals of SFR. The top of the diagram shows typical $\mathrm{Ca}^{2+}$ transients in the muscle of CONT rat; the bottom part shows typical $\mathrm{Ca}^{2+}$ transients in the muscle of MCT rat. The center of the plot shows typical SFR measured in the muscles from CONT and MCT rats. Arrows indicate time intervals where $\mathrm{Ca}^{2+}$ transients were collected

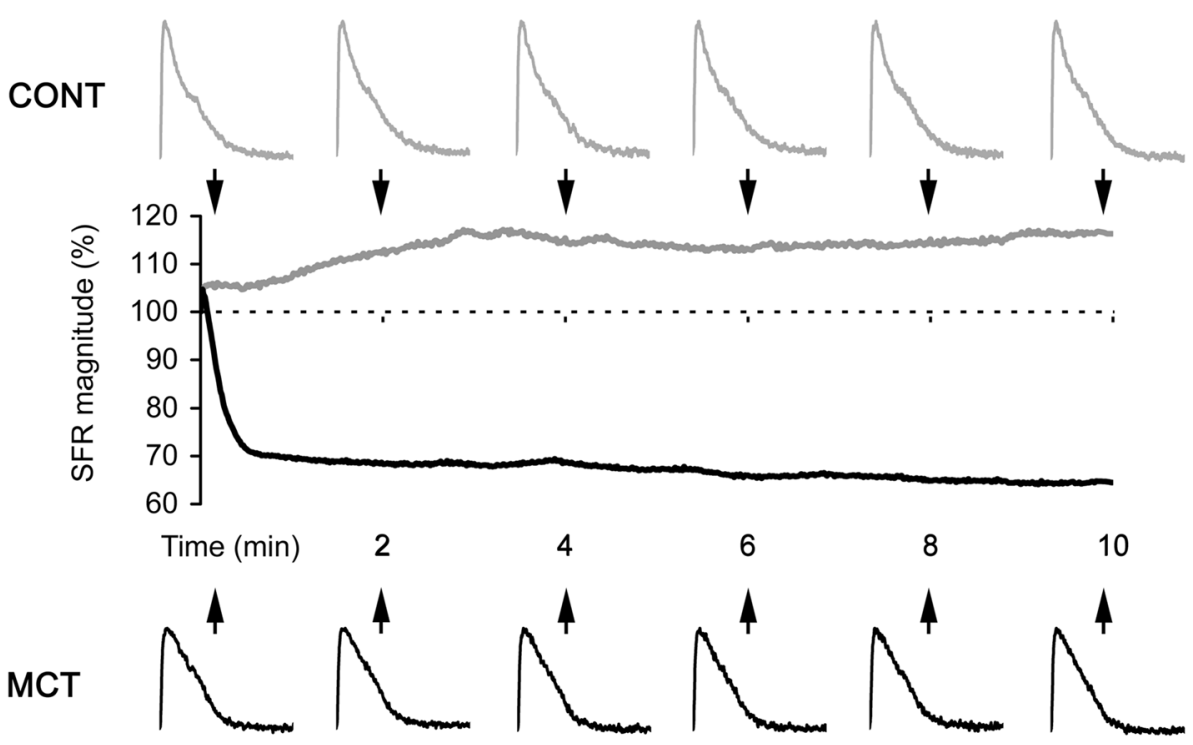

while these "bump" characteristics in MCT muscles slowly decreased over time (Fig. 4a, b). At the end of the response (at $10 \mathrm{~min}$ after stretch), the mean values of "bump" amplitude amounted to $120.2 \pm 6.9 \%$ and to $74.2 \pm 14.3 \%$ of the first value after stretch in healthy myocardium and failing myocardium of monocrotaline-treated rats, respectively (mean $\pm \mathrm{SD}, P=0.0039$, Mann-Whitney $U$ test). The mean values of "bump" integral intensity at the same stage of SFR (at the end of $10 \mathrm{~min}$ ) amounted to $139.4 \pm 11.2 \%$ and to $72.7 \pm 14.0 \%$ of the first value after stretch in CONT and MCT groups, respectively (mean $\pm \mathrm{SD}, P=0.0039$, Mann-Whitney $U$ test). A much less regular change in "bump" time-to-peak was found both in CONT and MCT groups (Fig. 4c) and this parameter showed non-significant elevation during SFR in both groups $(P=0.116$ and $P=0.075$ for CONT and MCT, respectively, Wilcoxon matched pairs test). Also, at the end of a 10-min interval of sustained stretch, the values of "bump" time-to-peak in CONT and MCT groups were, respectively, $106.8 \pm 11.1 \%$ and $108.8 \pm 20.0 \%$ of the first value after stretch (mean $\pm \mathrm{SD}$, non-significant difference, $P=1.0$, Mann-Whitney $U$ test). These findings indicate that the amount, rather than the timing properties, of the $\mathrm{Ca}-\mathrm{TnC}$ kinetics plays a role in the expression of SFR in rat cardiac muscle. 

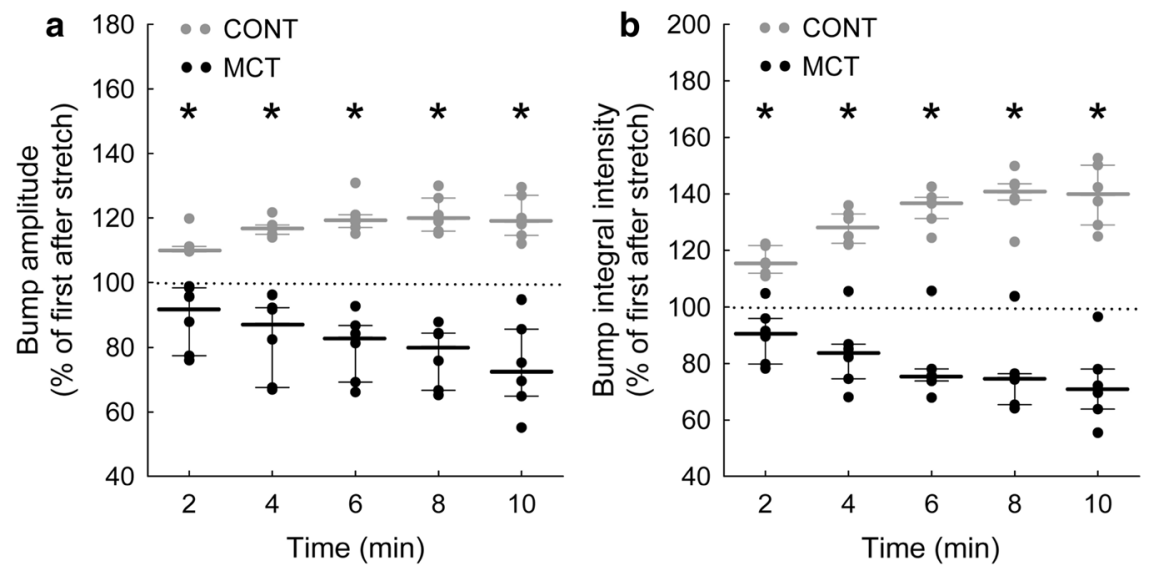

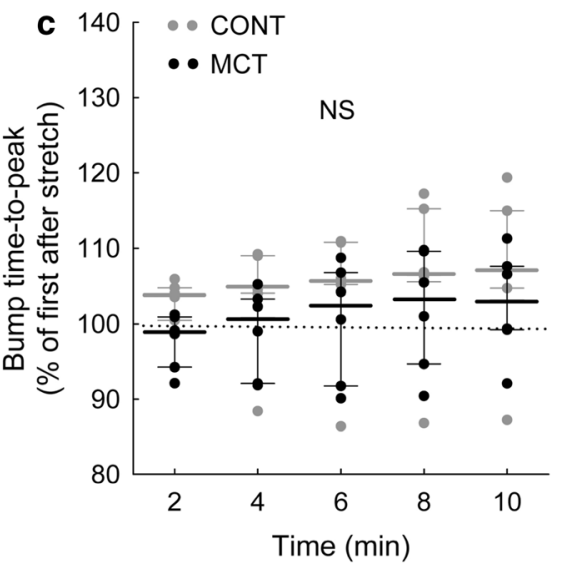

Fig. 4 The time-based changes of the $\mathrm{Ca}^{2+}$ transient "bump" characteristics during slow force response to sudden stretch. The changes in $\mathrm{Ca}^{2+}$ transient "bump" characteristics during the development of slow force response in normal $(n=6)$ and failing $(n=6)$ rat myocardium. a "Bump" amplitude. b "Bump" integral intensity. c "Bump" timeto-peak. All the characteristics are presented as a percentage of the first value after stretch. Scatter-plots of raw data (dots), median value (long thick lines) and 25-75\% percentiles (short thin lines) are shown. The dotted line shows the level of "no change." Asterisks indicate that the mean values are significantly different between CONT and MCT groups for the given time (Mann-Whitney $U$ test, $P<0.05$ ). $N S$ no significant difference

\section{Slow changes in "difference curve" characteristics in response to stretch}

Figure 5 summarizes time-based changes in the amplitude, integral intensity and time-to-peak of the "positive" component of "difference curve", obtained by subtraction of the $\mathrm{Ca}^{2+}$ transient measured immediately after stretch from the $\mathrm{Ca}^{2+}$ transients measured at 2, 4, 6, 8 or 10 min after the stretch, for healthy and failing rat myocardium. Note that these characteristics are presented in actual values, not as a percentage of the first value after stretch. This is due to the feature of the method of the "difference curve" where $\mathrm{Ca}^{2+}$ transient immediately after stretch (0 min after stretch) was used as a referent.

At the early stage of sustained stretch, there is an increase in the amplitude and integral intensity of the "positive" component of the "difference curve" both in healthy and failing rat myocardium (Fig. 5a, b). However,

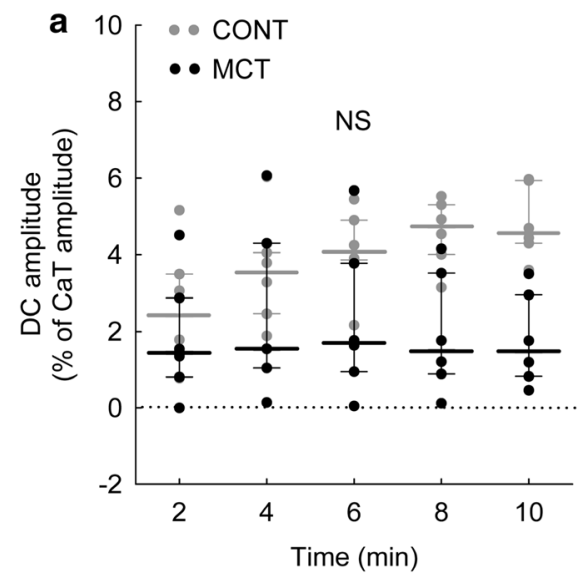

Fig. 5 The time-based changes of characteristics of the "difference curve" ("positive" component) during slow force response to sudden stretch. The changes in the characteristics of the "positive" component of the "difference curve", obtained by subtraction of referent $\mathrm{Ca}^{2+}$ transient from a current one, during the development of slow force response in normal $(n=6)$ and failing $(n=6)$ rat myocardium. a Amplitude of the "positive" component of the "difference curve." b Integral intensity of the "positive" component of the "difference
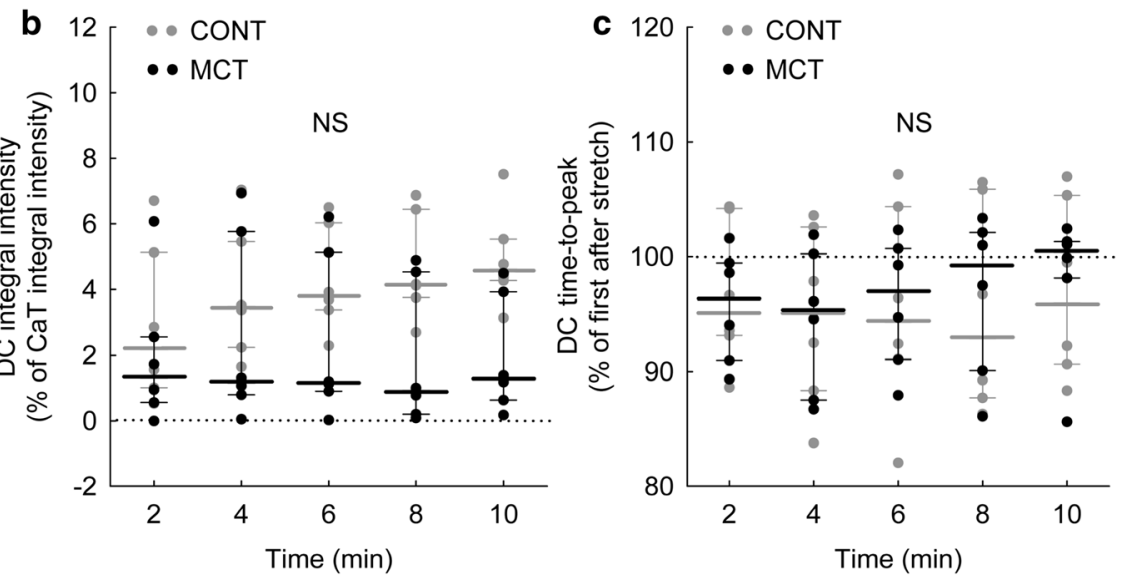

curve." c Time-to-peak of the "positive" component of the "difference curve." DC, "difference curve"; $\mathrm{CaT}, \mathrm{Ca}^{2+}$ transient. Note that the characteristics are presented in actual values, not as a percentage of the first value after stretch. Scatter-plots of raw data (dots), median values (long thick lines) and $25-75 \%$ percentiles (short thin lines) are shown. The dotted line shows the level of "no change." NS, no significant difference was found between CONT and MCT groups for the given time interval (Mann-Whitney $U$ test) 
only the CONT group displayed slow additional elevation of the values of these parameters during SFR whereas those in the MCT group remained virtually unchanged. For instance, the amplitude of the "positive" component of the "difference curve" in the CONT group increased from $2.7 \pm 1.5 \%$ of $\mathrm{Ca}^{2+}$ transient amplitude at the 2 -min point to $4.8 \pm 0.9 \%$ of $\mathrm{Ca}^{2+}$ transient amplitude at the 10 -min point (mean $\pm \mathrm{SD}$, significant difference, $P=0.027$, Wilcoxon matched pairs test). In contrast, in the MCT group this parameter was $1.9 \pm 1.6 \%$ and $1.8 \pm 1.2 \%$ of $\mathrm{Ca}^{2+}$ transient amplitude at the 2-min and 10-min time points after the stretch (mean $\pm \mathrm{SD}$, non-significant difference, $P=0.753$, Wilcoxon matched pairs test). The integral intensity of the "difference curve" increased from $3.0 \pm 2.4 \%$ to $4.9 \pm 1.5 \%$ of $\mathrm{Ca}^{2+}$ transient integral intensity (the area under the $\mathrm{Ca}^{2+}$ transient curve) at the 2 -min time point vs the 10 -min time point, respectively; the change was significant $(P=0.028$, Wilcoxon matched pairs test). The MCT group showed no significant time-dependent variation of the value of this parameter: $2.0 \pm 2.2 \%$ and $2.0 \pm 1.8 \%$ of $\mathrm{Ca}^{2+}$ transient integral intensity at 2 -min and 10 -min time points, respectively ( $P=0.92$, Wilcoxon matched pairs test). On the other hand, no significant difference was observed between the mean values of CONT vs MCT group collected for any given time interval (Fig. 5a, b). Similarly, the mean values of "bump" time-to-peak were not significantly affected by sudden stretch in either group, and were insignificant between the two groups regardless of the time interval (Fig. 5c).
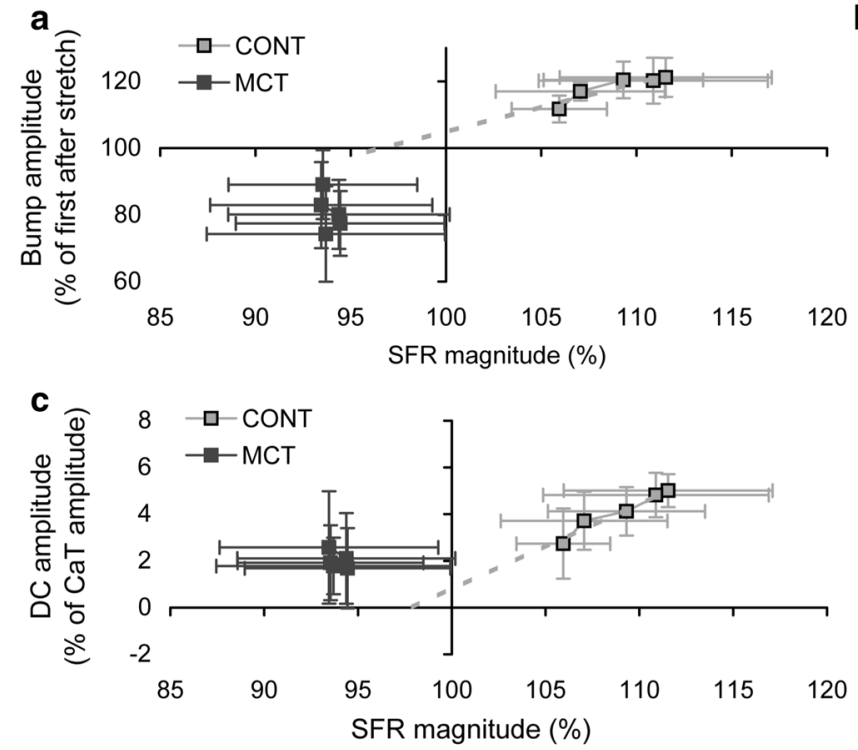

Fig. 6 The relations between time-matched SFR magnitude and the slow changes in the characteristics of the $\mathrm{Ca}^{2+}$ transient "bump" or "difference curve." a "Bump" amplitude is plotted against SFR magnitude. b "Bump" integral intensity is plotted against SFR magnitude. $\mathbf{c}$ The amplitude of the "positive" component of the "difference

\section{The correlation between SFR and slow changes in the characteristics of $\mathrm{Ca}^{2+}$ transient decay}

Due to the high variability of the calculated data (amplitude, integral intensity etc., see Fig. 5) it is uncertain how the slow changes in the characteristics of the $\mathrm{Ca}^{2+}$ transient relate to the magnitude of slow force response. To provide detailed insight to the possible mutual changes in peak isometric tension and the properties of $\mathrm{Ca}^{2+}$ transient decay, we analyzed the characteristics of $\mathrm{Ca}^{2+}$ transient decay (the amplitude and integral intensity of the "bump" and the "positive" component of the "difference curve") being plotted against SFR magnitude in a time-matched manner (Fig. 6). In healthy rat myocardium, we found a high correlation between slow increase in active tension and slow increase in these characteristics of the "bump" and "difference curve." For example, the determination of the coefficients ( $R^{2}$ values) of linear approximation used for the relationships of the CONT group, which are presented in Fig. 6, were all between 0.94 and 0.99 . This visual representation also revealed that the linear approximation for the averaged data obtained from healthy myocardium, if extended to the interception of the two axes, comes near to the "no change" point. In other words, if SFR magnitude is $\sim 100 \%$, i.e., no or negligible slow changes in active tension detected during SFR, then the "bump" or "difference curve" characteristics show minimal change relative to the value in the first twitch after stretch.

In contrast, there was a lack of regularity between slow changes in active tension and slow changes in the

\section{b}

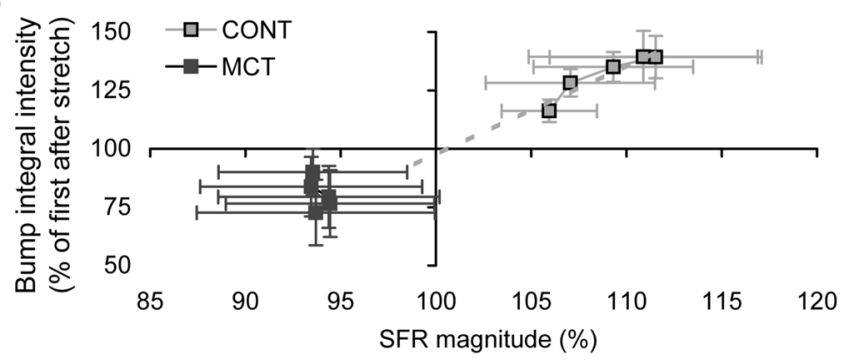

d

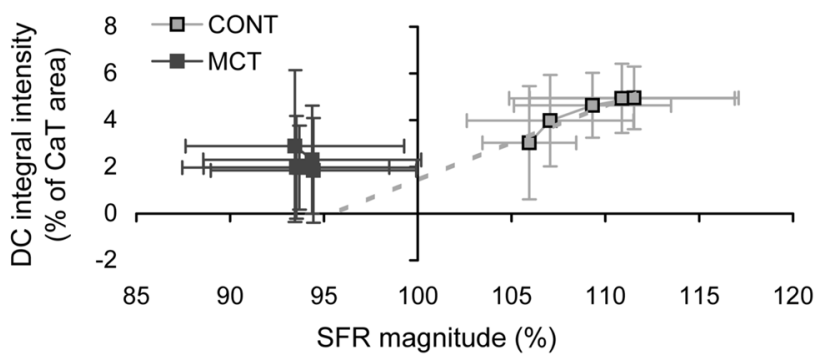

curve" is plotted against SFR magnitude. d The integral intensity of the "positive" component of the "difference curve" is plotted against SFR magnitude. DC, "difference curve"; $\mathrm{CaT}, \mathrm{Ca}^{2+}$ transient. Data is shown as mean $\pm \mathrm{SD}$. Dashed lines show linear approximation for CONT data 
characteristics of "bump" or "difference curve" of the $\mathrm{Ca}^{2+}$ transient. While the "bump" amplitude and "bump" integral intensity, if plotted against SFR magnitude, did show quite high $R^{2}$ values of linear approximation $(0.7$ and 0.82 , respectively, Fig. 6a, b), the actual change of these characteristics had no reasonable dependence on SFR magnitude, since the mean value points were spread in a very dense space on the $X$ axis ( $2 \%$ of SFR magnitude) and progressed in parallel to the $Y$ axis only. The amplitude and integral intensity of the "positive" component of the "difference curve" were totally uncoupled with slow changes in active tension, since the linear approximations of the mean data relationships showed $R^{2}$ values of 0.07 and 0.21 , respectively (Fig. 6c, d). The result indicates that the stretch does modify $\mathrm{Ca}^{2+}$ transient decay in both healthy and failing myocardia; however, no contemporary slow changes in $\mathrm{Ca}^{2+}$ transient decay are presented in the failing rat heart, compared to normal hearts. The interpretation of the finding is that the slow modulation of $\mathrm{Ca}-\mathrm{TnC}$ kinetics, typical for healthy cardiac muscle, and possibly playing a key role in the slow force response, is substantially impaired or has even vanished in the failing myocardium.

In the final step of our study, we compared the calculated dependences obtained by use of "bump" and "difference curve" of $\mathrm{Ca}^{2+}$ transient decay, in order to reveal whether the methods are interchangeable. Since we obtained a reasonable correlation between the mechanics and $\mathrm{Ca}$ transient decay only for the control group of muscles, we compared those sets of data. We plotted the above stated dependences (amplitude and integral intensity) of the "bump" and the "positive" component of the "difference curve" against SFR magnitude and superimposed them (Fig. 7). Importantly, we found a good degree of similarity between the methods in regards to calculated relationships, in spite of the methods having principally different initial steps of analysis. As shown in Fig. 7a, c, there is some dissimilarity between the calculation of the amplitudes of the "bump" and the "positive" component of the "difference curve", so the plot does not follow a straight line. In contrast, the relationships between SFR magnitude and the integral intensities of the "bump" and the "positive" component of the "difference curve" showed very high coincidence (Fig. 7b). If integral intensities of the "bump" and the "positive" component of the "difference curve" are plotted against each other, this relation was found to be quasilinear (Fig. 7d). Accordingly, we can confirm the applicability of the method of the "difference curve" to reveal changes in the $\mathrm{Ca}^{2+}$ transient decay phase, similarly to the previously used method of "bump" analysis.
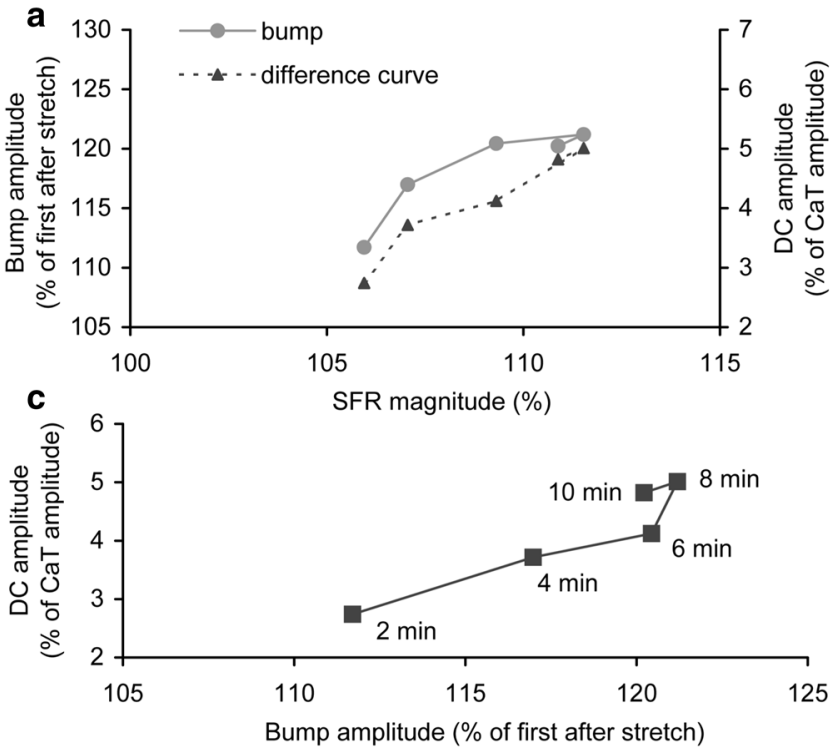

Fig. 7 The comparison of calculation similarities between the methods of "bump" and "difference curve" used to characterize $\mathrm{Ca}^{2+}$ transient decay during slow force response to sudden stretch (in CONT group only). a The amplitudes of "bump" and the "positive" component of the "difference curve" are plotted against SFR magnitude. b The integral intensities of "bump" and the positive "component" of the "difference curve" are plotted against SFR magnitude. Note use of secondary axis in panels a and b. c Amplitudes of "bump" and "posi-
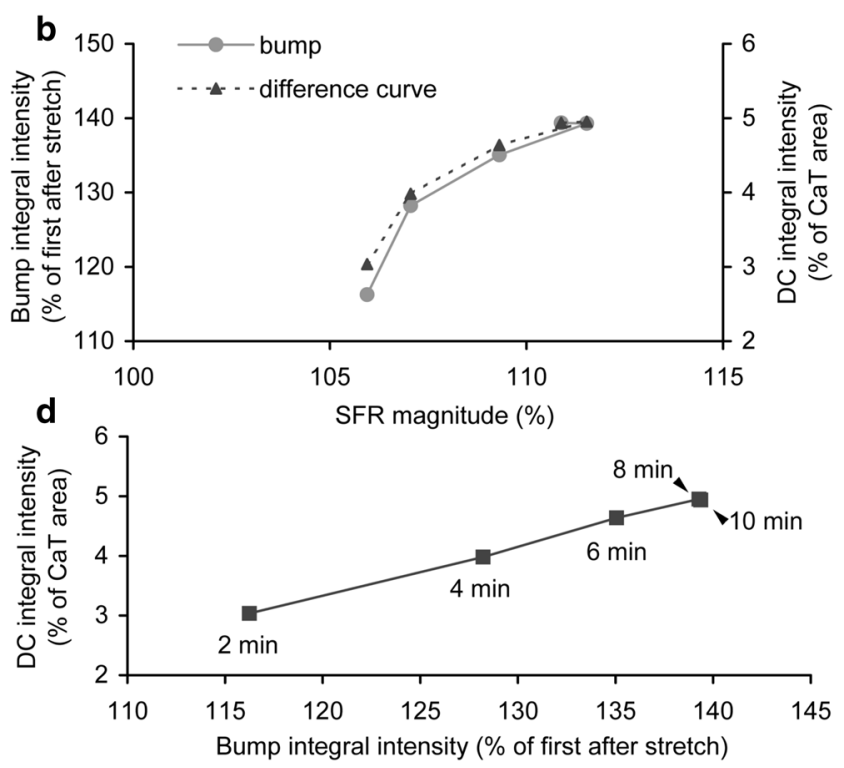

tive" component of the "difference curve" are plotted against each other. d Integral intensities of "bump" and "positive" component of the "difference curve" are plotted against each other. $D C$, "difference curve"; $\mathrm{CaT}, \mathrm{Ca}^{2+}$ transient. Mean values are shown. Labels on panels $\mathbf{c}$ and $\mathbf{d}$ show time interval after stretch which corresponds to the nearest point. Arrows on panel d show the exact position of the point for time intervals labeled " $8 \mathrm{~min}$ " and "10 min" 


\section{Discussion}

For the first time we obtained evidence of interrelation between the magnitude of slow force increase and slow changes in $\mathrm{Ca}^{2+}$ transient decay in healthy rat cardiac muscles subjected to sudden stretch. This interrelation could indicate that there is a direct interplay between slowly developed modulation of $\mathrm{Ca}-\mathrm{TnC}$ kinetics and additional activation of muscle contraction. The results obtained show that the percentage increase in peak active tension during slow response is substantially lower than that of certain characteristics of the $\mathrm{Ca}^{2+}$ transient "bump." For example, in our set of muscles from healthy hearts the maximum SFT magnitude was $~ 10 \%$ over the force at first twitch after stretch, while the "bump" integral intensity achieved $\sim 40 \%$ over the first value after stretch at the end of response. Also, the time-matched plots of SFR magnitude vs "bump" or "difference curve" amplitude/integral intensity showed saturation-like behavior, i.e., with large changes at the beginning of the response but minor changes at the end of the response (see Fig. 6). This may indicate that there is a "gain coefficient" between slow modulation of $\mathrm{Ca}-\mathrm{TnC}$ kinetics and additional activation of contraction.

In failing rat myocardium, we observed a blunted or even negative slow force response to sudden stretch, as has been reported previously $[8,9,29,31]$. This deficiency in SFR magnitude was accompanied by the deficiency in slow changes in $\mathrm{Ca}^{2+}$ transient decay. Moreover, the contemporary changes in peak active force and $\mathrm{Ca}^{2+}$ transient decay during the progress of the slow response were significantly depressed so the interrelation between them was low or negligible. Indeed, the linear approximation between SFR magnitude and certain characteristics of $\mathrm{Ca}^{2+}$ transient decay, retrieved on the basis of the methods of "bump" and "difference curve", was poor enough so as to have determination coefficients $R^{2}<0.1$.

Combined together, these findings demonstrate the potential role of the kinetics of $\mathrm{Ca}^{2+}$ extrusion from the cytosol, as monitored by $\mathrm{Ca}^{2+}$ transients, in the expression of slow force response. Yet, the slow drift of $\mathrm{Ca}^{2+}$ transient decay properties may reflect the slowly progressing changes in the kinetics of Ca-utilizing mechanisms following thesudden change in muscle length. $\mathrm{Ca}^{2+}$ buffering by troponin $\mathrm{C}$ is one of the potent mechanisms contributing to the magnitude of SFR and this buffer capacity depends both on sarcomere length and the function of the cardiac cell. It is known that failing myocardium has decreased length-dependence of $\mathrm{Ca}^{2+}$ sensitivity of myofilaments which accounts for the blunted Frank-Starling mechanism and may contribute to a depressed slow force response $[8,9,32]$. However, the length-induced effects on myofilament activation seem not to be the only mechanism for slow modulation of contraction, because positive SFR (while lower than in a normal heart) was observed in human failing ventricular and atrial myocardium [7, 9, 26]. The impaired function of mitochondria in failing hearts results in lowered ATP content available for recycling of myosin cross-bridges and this, via cooperative activation of myofilaments, affects the total amount of $\mathrm{Ca}-\mathrm{TnC}$ complexes activated during the contraction cycle $[32,33]$. Importantly, the kinetic properties of association and dissociation of $\mathrm{Ca}^{2+}$ and $\mathrm{TnC}$ strongly modulate relaxation of cardiac muscle, the $\mathrm{Ca}^{2+}$ content in intracellular $\mathrm{Ca}^{2+}$ stores and the contractile ability of cardiomyocytes in the following beat cycle(s) $[34,35]$. For instance, the elevated amount of $\mathrm{Ca}^{2+}$ utilized by $\mathrm{TnC}$ and/or total prolongation of $\mathrm{Ca}-\mathrm{TnC}$ kinetics affects the $\mathrm{Ca}^{2+}$ load in sarcoplasmic reticulum (SR) via modulation of SERCA2a function, and this may result in a slow increase in $\mathrm{Ca}^{2+}$ transient amplitude $[3,36,37]$. Indeed, it has been shown that $\mathrm{Ca}^{2+}$ transient amplitude is not rapidly increased immediately after the sudden stretch but progressively elevated during the slow force response [3, 38, 39]. Moreover, it has been reported that stretch-induced elevation of systolic pressure in a whole heart preparation does not relate to the changes in myoplasmic $\mathrm{Ca}^{2+}[40]$. Impaired function of SERCA2a in failing heart may distort the process of slow balancing of $\mathrm{Ca}^{2+}$ between cytosol and SR, including the contribution of a sodium-calcium exchanger (NCX) into this complex stabilization [35, 41-45]. The metabolic dysfunction, e.g., the depression of mitochondrial function by reduction of the content or activity of creatine kinase, is a key factor of such impairment of calcium homeostasis [46-48], while mitochondrial $\mathrm{Ca}^{2+}$ uptake plays a small role in the direct regulation of cytosolic calcium [28]. Also, a decrease in $\mathrm{Ca}^{2+}$ sensitization of myofilaments in the failing heart may contribute to the deficiency in positive SFR to stretch, similar to the negative force-frequency response in the failing myocardium $[49,50]$. Taken together, it may be concluded that the fine regulation of beat-to-beat increase in contractility after sudden stretch might be related to the slow $\mathrm{Ca}^{2+}$ redistribution between (intra)cellular compartments, arising predominantly from the beat-to-beat balancing between $\mathrm{Ca}-\mathrm{TnC}$ kinetics and SERCA2a function [34, 51]. Our results, obtained in failing rat myocardium, confirm this concept, because we observed here both negative SFR and the decrease in the magnitude of the $\mathrm{Ca}^{2+}$ transient "bump" and "difference curve." Yet, the most plausible situation is the combined effect of numerous mechanisms which affect $\mathrm{Ca}^{2+}$ transport across the cell membrane and/ or between intracellular $\mathrm{Ca}^{2+}$ stores (e.g., stretch-activated channels, store-operated calcium channels, NCX, change in intracellular $\mathrm{pH}$ etc., $[38,39,52])$ and the modulation of the intracellular $\mathrm{Ca}^{2+}$ cycle by the kinetics of $\mathrm{Ca}-\mathrm{TnC}$. 
The reason we say this, based on the present data, is the lack of prominent interrelation between the mechanics and free cytosolic $\mathrm{Ca}^{2+}$ kinetics in failing myocardium, where poor correlation was found between them. In the case of the ultimate role of $\mathrm{Ca}-\mathrm{TnC}$ kinetics in the slow force response, we must find the complete inversion of the responses (from positive to negative) in the failing heart, but minor distortion of the functional relation between the mechanics and $\mathrm{Ca}^{2+}$ transient decay must exist. On the other hand, in the failing rat myocardium we observed virtually no progression of slow change in active tension during SFR, just the immediate deficiency after the stretch. Therefore, the slow changes in $\mathrm{Ca}^{2+}$ transient decay may be too little to be adequately detected in the response, and this severely affects the observed relation between SFR magnitude and certain characteristics of $\mathrm{Ca}^{2+}$ transient decay.

In the present study we introduced our new method of "difference curve" designed specifically to analyze the $\mathrm{Ca}^{2+}$ transient decay phase in order to reveal whether the slow force changes are related to the changes in this decay. In our recent studies we found a lack of the length-dependent change in "bump" amplitude and integral intensity of $\mathrm{Ca}^{2+}$ transients measured in the right ventricular trabeculae of monocrotaline-treated rats with prominent signs of heart failure [29-31]. In fact, we observed the deficiency in the "bump" itself in those preparations, but their $\mathrm{Ca}^{2+}$ transients still had substantial and progressive change in the decay phase, which were in parallel with gradual stretch. Therefore, we needed to develop an alternative approach to investigate how stretch of the muscle modulates its $\mathrm{Ca}^{2+}$ transient. Dissimilar to the method of "bump" analysis where each $\mathrm{Ca}^{2+}$ transient is inspected independently for the monotonic decay and non-monotonic "bump" [30], the method of "difference curve" is related to the difference between a referent $\mathrm{Ca}^{2+}$ transient (assumed to be the state before the effect) and each consecutive $\mathrm{Ca}^{2+}$ transient (the progression of the effect). Also, the principal difference between the "bump" and "difference curve" analysis is that the former is just a part of the $\mathrm{Ca}^{2+}$ transient decay while the latter follows $\mathrm{Ca}^{2+}$ transient decay, on the whole. This, therefore, makes it possible to study the changes in free cytosolic calcium kinetics occurring in a very early or late phase of $\mathrm{Ca}^{2+}$ transient decay.

The typical "difference curve" has three components (all can be seen in Fig. 1d). The first upward component occurs within $20-30 \mathrm{~ms}$ from the stimulus, indicating that there is some stretch-related effect on calcium-induced calcium release; it virtually coincides with the peak of the $\mathrm{Ca}^{2+}$ transient and therefore is not related to the lengthinduced changes in $\mathrm{Ca}^{2+}$ utilization by troponin $\mathrm{C}$. The exact mechanism for this component is unknown but it may occur due to additional $\mathrm{Ca}^{2+}$ entering the cell via $\mathrm{NCX}$ or stretch-activated channels. The "negative" downward component starts to develop nearly around the $\mathrm{Ca}^{2+}$ transient peak and lasts several tens of milliseconds. Probably, it corresponds to the fast $\mathrm{Ca}^{2+}$-utilization by $\mathrm{TnC}$ in stretched muscle, giving the decreased free cytosolic $\mathrm{Ca}^{2+}$ compared with the non-stretched muscle. However, this component was found to be not very dependent on the stretch of the muscle, compared to the third "positive" upward component which is greatly influenced by stretch of the muscle, both in regards to amplitude and timing properties. For example, under gradual stretch (e.g., in force-length relation) this component shows a large increase in amplitude and integral intensity accompanied by substantial deceleration of its development, i.e., by an increase in time-to-peak. All these length-induced changes indicate that this "positive" component may be highly related to the kinetics of $\mathrm{Ca}-\mathrm{TnC}$ interaction which is augmented and prolonged in stretched muscle, compared to the non-stretched state. Therefore, in our manuscript we have focused on this component of the "difference curve" only, while omitting the first two components from the analysis.

The method of the "difference curve" does not require special algorithms to find any specific part of the $\mathrm{Ca}^{2+}$ transient decay, unlike the "bump" method of analysis, though some calculations are needed to distinguish between "negative" and "positive" components (see Fig. 1d). Finally, and importantly, in the opinion of the authors, the method of "difference curve" is invariant to the occurrence of the specific "bump" on the $\mathrm{Ca}^{2+}$ transient decay, is applicable to transients of arbitrary shape, and therefore can follow prolonged and/or small changes in the kinetics of $\mathrm{Ca}^{2+}$ transient decay. Altogether, we conclude that the use of the "difference curve" instead of the "bump" is preferred in order to evaluate precisely the effects on $\mathrm{Ca}^{2+}$ transient decay during the relaxation phase of cardiac muscle.

The study has some methodological limitations. For instance, the measurements were done at a temperature and pacing rate substantially lower than the physiological conditions in rat myocardium. We were limited to these conditions since the Ca-sensitive fluorophore fura- 2 was subjected to rapid gradual photodeactivation at physiological temperature/pacing rate while the SFR measurements lasted tens of minutes. Also, in contrast to the previously reported slow rise in $\mathrm{Ca}^{2+}$ transient amplitude during slow force response $[3,12,18]$, we did not observe such changes except a few examples (please see Fig. $1 \mathrm{~S}$ in Supplemental data). It may be that cumulative photodegradation of fluorescent dye during long recordings lasting several tens of minutes (both due to the effect of periodical illumination, bleaching of the dye, and a temperature-related effect) contributes to the lack of increase in the $\mathrm{Ca}^{2+}$ transient amplitude. Another reason for discrepancies between our results and results provided by others may be the use of different fluorescent dyes (e.g., with 
different affinity to $\mathrm{Ca}^{2+}$ ) and/or different loading times. On the other hand, we focused on more precise assessment of the decay phase of the $\mathrm{Ca}^{2+}$ transient rather than its amplitude, as it has been agreed that the relaxation of cardiac muscle is a key step of the cardiac cycle and it needs to be highly balanced in order to keep adequate contraction of cardiac muscle during the following cycles [28]. Finally, we investigated the slow effects on force development in the isometric mode of contraction (constant length) but the contraction in vivo is a combination of both the isovolumic phase and systolic ejection (cycled shortening-re-lengthening). Limiting our measurements to the isometric condition, however, allowed us to reveal shortening-independent effects of sudden stretch to $\mathrm{Ca}^{2+}$ homeostasis in cardiac tissue.

In conclusion, intracellular mechanisms of slow adaptation of myocardial contractility after sudden stretch are disrupted in failing rat myocardium, as demonstrated by the poor interrelation between the decay phase of the $\mathrm{Ca}^{2+}$ transient (governed predominantly by SERCA2a and $\mathrm{Ca}-\mathrm{TnC}$ kinetics; the latter is assessed by the $\mathrm{Ca}^{2+}$ transient "bump" and "difference curve" methods) and the peak contractility. Metabolic dysfunction in the failing heart may contribute at least partially to the negative slow force response to stretch, in contrast to the substantial positive response observed in normal rat myocardium. The potential significance of this result is that the slow force response in diseased myocardium may be augmented under conditions affecting the kinetics of $\mathrm{Ca}-\mathrm{TnC}$ interaction and/or $\mathrm{Ca}^{2+}$ extrusion from the cytosol.

Acknowledgements The authors thank Daniil Kuznetsov for his help in the implementation of the monocrotaline-based experimental model of pulmonary hypertension in rats.

Funding The study was carried out within the framework of the IIF UrB RAS theme No AAAA-A18-118020590031-8, supported by RFBR (grants \#16-04-00545 and \#18-04-00572), by the Program of the Ural Branch of RAS (No. 18-7-4-15, AAAA-A18-118020590134-6) and by RF Government Act \#211 of March 16, 2013 (agreement 02.A03.21.0006).

\section{Compliance with ethical standards}

Conflict of interest The authors declare that they have no competing financial interests.

Ethical approval All applicable international, national, and/or institutional guidelines for the care and use of animals were followed. All procedures performed in studies involving animals were in accordance with the ethical standards of the local institutional ethics committee.

\section{References}

1. Cingolani HE, Pérez NG, Cingolani OH, Ennis IL (2013) The Anrep effect: 100 years later. Am J Physiol Heart Circ Physiol 304:H175-H182. https://doi.org/10.1152/ajpheart.00508.2012
2. Chen-Izu Y, Izu LT (2017) Mechano-chemo-transduction in cardiac myocytes. J Physiol 595(12):3949-3958. https://doi. org/10.1113/JP273101

3. Kentish JC, Wrzosek A (1998) Changes in force and cytosolic $\mathrm{Ca} 2+$ concentration after length changes in isolated rat ventricular trabeculae. J Physiol 506:431-444

4. Todaka K, Ogino K, Gu A, Burkhoff D (1998) Effect of ventricular stretch on contractile strength, calcium transient, and cAMP in intact canine hearts. Am J Physiol Heart Circ Physiol 274(43):H990-H1000

5. von Lewinski D, Stumme B, Maier LS, Luers C, Bers DM, Pieske B (2003) Stretch-dependent slow force response in isolated rabbit myocardium is $\mathrm{Na}+$ dependent. Cardiovasc Res 57:1052-1061. https://doi.org/10.1016/S0008-6363(02)00830-1

6. Calaghan S, White E (2004) Activation of $\mathrm{Na}+-\mathrm{H}+$ exchange and stretch-activated channels underlies the slow inotropic response to stretch in myocytes and muscle from the rat heart. J Physiol 559:205-214. https://doi.org/10.1113/jphysiol.2004.069021

7. Kockskämper J, von Lewinski D, Khafaga M, Elgner A, Grimm M, Eschenhagen T, Gottlieb PA, Sachs F, Pieske B (2008) The slow force response to stretch in atrial and ventricular myocardium from human heart: functional relevance and subcellular mechanisms. Prog Biophys Mol Biol 97:250-267. https://doi. org/10.1016/j.pbiomolbio.2008.02.026

8. Brixius K, Reuter H, Bloch W, Schwinger RH (2005) Altered hetero- and homeometric autoregulation in the terminally failing human heart. Eur J Heart Fail 7:29-35. https://doi.org/10.1016/j. ejheart.2004.03.018

9. von Lewinski D, Kockskamper J, Zhu D, Post H, Elgner A, Pieske B (2009) Reduced stretch-induced force response in failing human myocardium caused by impaired $\mathrm{Na}+$ - contraction coupling. Circ Heart Fail 2:47-55. https://doi.org/10.1161/CIRCHEARTF AILURE.108.794065

10. Buyandelger B, Mansfield C, Knöll R (2014) Mechano-signaling in heart failure. Pflugers Arch 466:1093-1099. https://doi. org/10.1007/s00424-014-1468-4

11. Neves JS, Leite-Moreira AM, Neiva-Sousa M, Almeida-Coelho J, Castro-Ferreira R, Leite-Moreira AF (2016) Acute myocardial response to stretch: what we (don't) know. Front Physiol 6:408. https://doi.org/10.3389/fphys.2015.00408

12. Ward M-L, Williams IA, Chu Y, Cooper PJ, Ju Y-K, Allen DG (2008) Stretch-activated channels in the heart: contributions to length-dependence and to cardiomyopathy. Prog Biophys Mol Biol 97:232-249. https://doi.org/10.1016/j.pbiomolbio .2008.02.009

13. Cingolani HE, Pérez NG, Pieske B, von Lewinski D, Camilion de Hurtado MC (2003) Stretch-elicited $\mathrm{Na}+/ \mathrm{H}+$ exchanger activation: the autocrine/paracrine loop and its mechanical counterpart. Cardiovasc Res 57:953-960. https://doi.org/10.1016/S0008 -6363(02)00768-X

14. Pérez NG, Nolly MB, Roldan MC, Villa-Abrille MC, Cingolani E, Portiansky EL, Alvarez BV, Ennis IL, Cingolani HE (2011) Silencing of NHE-1 blunts the slow force response to myocardial stretch. J Appl Physiol 111:874-880. https://doi.org/10.1152/jappl physiol.01344.2010

15. Cingolani OH, Pérez NG, Ennis IL, Alvarez MC, Mosca SM, Schinella GR, Escudero EM, Cónsole G, Cingolani HE (2011) In vivo key role of reactive oxygen species and NHE-1 activation in determining excessive cardiac hypertrophy. Pflügers Arch 462:733-743. https://doi.org/10.1007/s00424-011-1020-8

16. Ennis IL, Aiello EA, Cingolani HE, Perez NG (2013) The autocrine/paracrine loop after myocardial stretch: mineralocorticoid receptor activation. Curr Cardiol Rev 9(3):230-240. https://doi. org/10.2174/1573403X113099990034

17. Prosser BL, Khairallah RJ, Ziman AP, Ward CW, Lederer WJ (2013) X-ROS signaling in the heart and skeletal muscle: 
stretch-dependent local ROS regulates [Ca2+]i. J Mol Cell Cardiol 58:172-181. https://doi.org/10.1016/j.yjmcc.2012.11.011

18. Seo K, Rainer PP, Lee DI, Hao S, Bedja D, Birnbaumer L, Cingolani OH, Kass DA (2014) Hyperactive adverse mechanical stress responses in dystrophic heart are coupled to transient receptor potential canonical 6 and blocked by cGMP-protein kinase G modulation. Circ Res 114(5):823-832. https://doi.org/10.1161/ CIRCRESAHA.114.302614

19. Yamaguchi Y, Iribe G, Kaneko T, Takahashi K, Numaga-Tomita T, Nishida M, Birnbaumer L, Naruse K (2018) TRPC3 participates in angiotensin II type 1 receptor-dependent stress-induced slow increase in intracellular $\mathrm{Ca} 2+$ concentration in mouse cardiomyocytes. J Physiol Sci 68(2):153-164. https://doi.org/10.1007/ s12576-016-0519-3

20. Prakriya M, Lewis RS (2015) Store-operated calcium channels. Physiol Rev 95:1383-1436. https://doi.org/10.1152/physrev.00020 .2014

21. Xu N, Cioffi DL, Alexeyev M, Rich TC, Stevens T (2015) Sodium entry through endothelial store-operated calcium entry channels: regulation by Orai1. Am J Physiol Cell Physiol 308:C277-C288. https://doi.org/10.1152/ajpcell.00063.2014

22. Kobirumaki-Shimozawa F, Inoue T, Shintani SA, Oyama K, Terui T, Minamisawa S, Ishiwata S, Fukuda N (2014) Cardiac thin filament regulation and the Frank-Starling mechanism. J Physiol Sci 64:221-232. https://doi.org/10.1007/s12576-014-0314-y

23. Pulcastro HC, Awinda PO, Methawasin M, Granzier H, Dong W, Tanner BCW (2016) Increased titin compliance reduced lengthdependent contraction and slowed cross-bridge kinetics in skinned myocardial strips from Rbm ${ }^{20 \Delta R R M}$ mice. Front Physiol 7:322. https://doi.org/10.3389/fphys.2016.00322

24. Ait-Mou Y, Zhang M, Martin JL, Greaser ML, de Tombe PP (2017) Impact of titin strain on the cardiac slow force response. Prog Biophys Mol Biol 130(Pt B):281-287. https://doi. org/10.1016/j.pbiomolbio.2017.06.009

25. Sequeira V, van der Velden J (2017) The Frank-Starling law: a jigsaw of titin proportions. Biophys Rev 9:259-267. https://doi. org/10.1007/s12551-017-0272-8

26. von Lewinski D, Stumme B, Fialka F, Luers C, Pieske B (2004) Functional relevance of the stretch-dependent slow force response in failing human myocardium. Circ Res 94:1392-1398. https://doi. org/10.1161/01.RES.0000129181.48395.ff

27. Janssen PM (2010) Kinetics of cardiac muscle contraction and relaxation are linked and determined by properties of the cardiac sarcomere. Am J Physiol Heart Circ Physiol 299:H1092-H1099. https://doi.org/10.1152/ajpheart.00417.2010

28. Biesiadecki BJ, Davis JP, Ziolo MT, Janssen PML (2014) Trimodal regulation of cardiac muscle relaxation; intracellular calcium decline, thin filament deactivation, and crossbridge cycling kinetics. Biophys Rev 6:273-289. https://doi.org/10.1007/s1255 1-014-0143-5

29. Lookin O, Balakin A, Protsenko Y (2018) Inhibition of AT1 receptors by losartan affects myocardial slow force response in healthy but not in monocrotaline-treated young rats. Gen Physiol Biophys 37(2):153-162. https://doi.org/10.4149/gpb_2017025

30. Lookin O, Balakin A, Kuznetsov D, Protsenko Y (2015) The length-dependent activation of contraction is equally impaired in impuberal male and female rats in monocrotaline-induced right ventricular failure. Clin Exp Pharmacol Physiol 42(11):11981206. https://doi.org/10.1111/1440-1681.12471

31. Lookin O, Kuznetsov D, Protsenko Y (2015) Sex differences in stretch-dependent effects on tension and $\mathrm{Ca} 2+$ transient of rat trabeculae in monocrotaline pulmonary hypertension. J Physiol Sci 65:89-98. https://doi.org/10.1007/s12576-014-0341-8

32. Hanft LM, Korte FS, McDonald KS (2008) Cardiac function and modulation of sarcomeric function by length. Cardiovasc Res 77(4):627-636. https://doi.org/10.1093/cvr/cvm099
33. Luo M, Anderson ME (2013) Mechanisms of altered Ca2+handling in heart failure. Circ Res 113:690-708. https://doi. org/10.1161/CIRCRESAHA.113.301651

34. Trafford AW, Díaz ME, Eisner DA (2001) Coordinated control of cell $\mathrm{Ca} 2+$ loading and triggered release from the sarcoplasmic reticulum underlies the rapid inotropic response to increased L-type Ca2+ current. Circ Res 88:195-201. https://doi. org/10.1161/01.RES.88.2.195

35. Dibb KM, Eisner DA, Trafford AW (2007) Regulation of systolic $[\mathrm{Ca} 2+] \mathrm{i}$ and cellular $\mathrm{Ca} 2+$ flux balance in rat ventricular myocytes by SR Ca2+, L-type Ca2+ current and diastolic [Ca2+]i. J Physiol 585:579-592. https://doi.org/10.1113/jphysiol.2007.141473

36. Periasamy M, Huke S (2001) SERCA pump level is a critical determinant of $\mathrm{Ca} 2+$ homeostasis and cardiac contractility. J Mol Cell Cardiol 33:1053-1063. https://doi.org/10.1006/ jmcc.2001.1366

37. Kho C, Lee A, Hajjar RJ (2012) Altered sarcoplasmic reticulum calcium cycling - targets for heart failure therapy. Nat Rev Cardiol 9(12):717-733. https://doi.org/10.1038/nrcardio.2012.145

38. Luers C, Fialka F, Elgner A, Zhu D, Kockskämper J, von Lewinski D, Pieske B (2005) Stretch-dependent modulation of [Na+] $\mathrm{i},[\mathrm{Ca} 2+] \mathrm{i}$, and $\mathrm{pHi}$ in rabbit myocardium-a mechanism for the slow force response. Cardiovasc Res 68:454-463. https://doi. org/10.1016/j.cardiores.2005.07.001

39. Shen X, Cannell MB, Ward M-L (2013) Effect of SR load and pH regulatory mechanisms on stretch-dependent $\mathrm{Ca} 2+$ entry during the slow force response. J Mol Cell Cardiol 63:37-46. https://doi. org/10.1016/j.yjmcc.2013.07.008

40. Rhodes SS, Camara AKS, Aldakkak M, Heisner JS, Stowe DF (2015) Stretch-induced increase in cardiac contractility is independent of myocyte $\mathrm{Ca} 2+$ while block of stretch channels by streptomycin improves contractility after ischemic stunning. Physiol Rep 3(8):e12486. https://doi.org/10.14814/phy2.12486

41. Baartscheer A, Schumacher CA, Belterman CNW, Coronel R, Fiolet JWT (2003) SR calcium handling and calcium after-transients in a rabbit model of heart failure. Cardiovasc Res 58:99-108. https ://doi.org/10.1016/S0008-6363(02)00854-4

42. Bers DM, Despa S (2006) Cardiac myocytes $\mathrm{Ca} 2+$ and $\mathrm{Na}+$ regulation in normal and failing hearts. J Pharmacol Sci 100:315-322. https://doi.org/10.1254/jphs.CPJ06001X

43. Ward M-L, Crossman DJ, Cannell MB (2011) Mechanisms of reduced contractility in an animal model of hypertensive heart failure. Clin Exp Pharmacol Physiol 38:711-716. https://doi.org/ 10.1111/j.1440-1681.2011.05563.x

44. ter Keurs HE (2012) The interaction of $\mathrm{Ca} 2+$ with sarcomeric proteins: role in function and dysfunction of the heart. Am J Physiol Heart Circ Physiol 302:H38-H50. https://doi.org/10.1152/ajphe art.00219.2011

45. Fernandez-Tenorio M, Niggli E (2018) Stabilization of Ca2+signaling in cardiac muscle by stimulation of SERCA. J Mol Cell Cardiol 119:87-95. https://doi.org/10.1016/j.yjmcc.2018.04.015

46. Lamberts RR, Caldenhoven E, Lansink M, Witte G, Vaessen RJ, St Cyr JA, Stienen GJ (2007) Preservation of diastolic function in monocrotaline-induced right ventricular hypertrophy in rats. Am J Physiol Heart Circ Physiol 293:H1869-H1876. https://doi. org/10.1152/ajpheart.00294.2007

47. Fowler ED, Benoist D, Drinkhill MJ, Stones R, Helmes M, Wüst RC, Stienen GJ, Steele DS, White E (2015) Decreased creatine kinase is linked to diastolic dysfunction in rats with right heart failure induced by pulmonary artery hypertension. J Mol Cell Cardiol 86:1-8. https://doi.org/10.1016/j.yjmcc.2015.06.016

48. Takeuchi A, Kim B, Matsuoka S (2015) The destiny of $\mathrm{Ca} 2+$ released by mitochondria. J Physiol Sci 65:11-24. https:// doi.org/10.1007/s12576-014-0326-7

49. Espejo MS, Aiello I, Sepúlveda M, Vila Petroff MG, Aiello EA, De Giusti VC (2017) The reduced myofilament responsiveness to 
calcium contributes to the negative force-frequency relationship in rat cardiomyocytes: role of reactive oxygen species and p-38 map kinase. Pflugers Arch 469:1663-1673. https://doi.org/10.1007/ s00424-017-2058-z

50. Hardy MEL, Pervolaraki E, Bernus O, White E (2018) Dynamic action potential restitution contributes to mechanical restitution in right ventricular myocytes from pulmonary hypertensive rats. Front Physiol 9:205. https://doi.org/10.3389/fphys.2018.00205

51. Briston SJ, Dibb KM, Solaro RJ, Eisner DA, Trafford AW (2014) Balanced changes in Ca buffering by SERCA and troponin contribute to $\mathrm{Ca}$ handling during $\beta$-adrenergic stimulation in cardiac myocytes. Cardiovasc Res 104(2):347-354. https://doi. org/10.1093/cvr/cvu201
52. Zhao ZH, Youm JB, Wang Y, Lee JH, Sung JH, Kim J-C, Woo SH, Leem CH, Kim SJ, Cui L, Zhang YH (2016) Cardiac inotropy, lusitropy, and $\mathrm{Ca} 2+$ handling with major metabolic substrates in rat heart. Pflugers Arch 468(11-12):1995-2006. https://doi. org/10.1007/s00424-016-1892-8

Publisher's Note Springer Nature remains neutral with regard to jurisdictional claims in published maps and institutional affiliations. 